\title{
A precariedade existencial como condição essencial de compreensão para a experiência religiosa na contemporaneidade
}

\author{
Existential precariousness as an essential condition of understanding for \\ religious experience in contemporaneity
}

Daniel Toledo*

\begin{abstract}
Resumo
O presente artigo versa sobre a referência ontológica de fundo da experiência religiosa em geral e tem como objetivo evidenciar em que medida a nossa condição existencial de finitude é impositiva para se compreender as mais variadas formas de manifestações dos fenômenos religiosos que afloram na contemporaneidade. Para isso, partiremos da distinção entre uma concepção hermenêuticofenomenológica da experiência religiosa em sua essência e as abordagens empíricas acerca das suas diversas configurações concretas. Ao cabo, tentaremos apontar que as possibilidades de apreensão dos fenômenos religiosos em geral são devedoras de um elemento existencial que nos é essencialmente constitutivo, a saber, a condição de precariedade do ser finito diante da abertura de sentido que o excede em seu horizonte de transcendência. Como contribuição geral, essa forma de compreensão apresentada deve vedar toda pretensão de tornar absoluto um sentido de fundo que deve permanecer em aberto enquanto a mais radical condição de possibilidade para o fenômeno religioso.
\end{abstract}

Palavras-chave: Precariedade existencial; condição ontológica; experiência religiosa; contemporaneidade.

\begin{abstract}
This study deals with the ontological background reference of religious experience in general, and it aimed to demonstrate how our existential condition of finitude is imposed to understand the most varied forms of manifestations of religious phenomena that arise in the contemporary world. Thus, we will start from the distinction between a hermeneutic-phenomenological conception of the religious experience in its essence and the empirical approaches on its diverse concrete configurations. In the end, we will try to point out that the possibilities of apprehension of religious phenomena in general lack an existential element that is essentially constitutive for us, namely, the condition of the precariousness of the finite being faced with the opening of meaning that exceeds it in its horizon of transcendence. As general contribution, this way of understanding must foreclose every claim to make absolute a background meaning that should remain open as the most radical condition of possibility for the religious phenomena.
\end{abstract}

Keywords: Existential precariousness; ontological condition; religious experience; contemporaneity.

Artigo submetido em 17 de abril de 2017 e aprovado em 29 de junho de 2017.

* Doutor, mestre e pós-doutor na área de concentração em Filosofia da Religião pelo PPCIR-UFJF e pela PUC-MG, Graduado em Filosofia (UFJF). Membro da Sociedade Brasileira de Filosofia da Religião (SBFR). Teve sua tese de doutorado publicada e indicada ao Prêmio Capes de Tese - Edição 2013. País de Origem: Brasil. E-mail: dasilvatoledo@yahoo.com.br

Horizonte, Belo Horizonte, v. 15, n. 46, p. 472-486, abr./jun. 2017 - ISSN 2175-5841 


\section{Introdução}

Para muitos estudiosos hodiernos, as metamorfoses atuais da experiência religiosa implicam em sua permanência, sendo suas transformações - quando comparadas com as formas historicamente tradicionais - compreendidas como estratégias de adaptação ao meio contextualizado no tempo e no espaço. Em tal cenário, "fenômeno religioso" seria uma noção subsistente por meio de toda e qualquer vivência que recebesse do próprio sujeito ou coletividade que a porta essa denotação possibilitada pelo seu quadro sociocultural. Dessa forma, as vivências dos fenômenos tidos como religiosos não poderiam ser remetidas a nenhuma espécie de epifenômeno de fundo transcendente ao tempo e ao espaço.

Frente a esse quadro, pesquisadores questionam também como poderíamos estabelecer uma possível chave de leitura unitária para o conceito de experiência religiosa, prescindindo de referenciais que ultrapassem a gama de recolhas das diversas categorias pragmáticas, através de procedimentos analíticos de dados objetivamente mesuráveis, de maneira estritamente empírica, já que essa experiência implicaria necessariamente uma concepção da pessoa humana que não deveria ser reduzida ou distorcida por uma racionalidade funcional ou meramente utilitária.

Como representação de um dos lados deste conflito, teríamos, ainda em termos sintéticos, um conceito substantivo de religião que, de sua parte, traz em si a pretensão de descrever a composição intrínseca de um sentido mais geral para a noção de religião que, em essência, não dependa de qualquer construto estrutural externo, devendo se antepor aos mesmos. Uma concepção que em geral se apoia predominantemente no pressuposto de uma determinada ligação espiritual do humano com o transcendente elevado acima da concretude fáctica, ainda que pretensamente determinante para a mesma. Em síntese, tratar-se-ia de pensar a religião a partir de elementos internos à condição espiritual humana. 
Em contrapartida, o conceito funcional de religião, por seu turno, implica basicamente a concepção de religião como catalisadora social, operando como doadora e receptora de sentido em relação ao meio histórico-cultural ao qual se integra, permeando dessa forma o contexto de mundo que abarca o indivíduo a partir de suas referências axiológicas. A lógica e a validade de uma religião devem ser tematizadas e demonstradas com vistas a exigências humanas plausíveis ligadas à interpretação e em conformidade a determinadas conduções de vida. Trata-se fundamentalmente de um conceito normativo, que pressupõe e estabelece a religião como um horizonte de sentido em estreita correlação com os valores concretos essencialmente constitutivos da estrutura social que engloba o agente humano enquanto sujeito histórico. Fenômenos religiosos, neste enquadramento, seriam todos os fenômenos aos quais poderíamos atribuir alguma conotação religiosa em termos de integração sociocultural.

De nossa parte, entendemos que uma compreensão essencial do fenômeno religioso não pode ter por pretensão escapar por inteiro aos limites de nossa condição existencial circunscrita de maneira fundamental ao horizonte da finitude. O marco maior dessa delimitação repousa na observância do fato fundamental de que "a finitude se choca com a pretensão do definitivo, do absoluto, da objetividade” (WACHHOLZ, 2011, p. 210).

Assumir como referência central o caráter de precariedade de nossa compreensão finita (limitada no tempo e no espaço) acerca dos fenômenos religiosos, em última instância é o que propomos aqui como pressuposto fundamental. A assunção primária dessa condição implica o reconhecimento de certa impotência radical do pensamento humano diante da projeção de determinações absolutas, por meio de atribuições entitativas que tenham por pretensão adjudicar às experiências religiosas uma formatação prévia específica como sua expressão objetivamente máxima. 
A finitude sustenta uma abertura de sentido que se perfaz como condição de possibilidade para a compreensão dos fenômenos que constituem a experiência religiosa em geral. É a partir da suspensão do sentido último que podemos situar não só as diferentes modalidades de manifestação dos fenômenos constitutivos da experiência religiosa, mas antes também a própria possibilidade do ser e do não ser dessa experiência, isto é, da presença e da ausência do próprio sentido religioso que, em confrontação com os demais fenômenos e experiências mundanas, pode sempre se redimensionar dinamicamente a tal ponto de se tornar fugaz frente às tentativas de apreensões que lhe são dirigidas.

O conjunto de possibilidades para as diversas formas de experiências religiosas marcadas pelo signo da finitude está essencialmente comprometido com os fenômenos de mundo que compõem a tessitura de totalidade de sentido na qual está enredado nosso próprio horizonte de compreensão existencial. Reconhecer a própria precariedade da compreensão finita (limitada no tempo e no espaço) acerca dos fenômenos religiosos em última instância é o que reivindicamos aqui como um horizonte de sentido que deve ser reportado à possibilidade de uma experiência fundamental. Essa experiência radicaliza-se ao atingir justamente a impotência radical do pensar diante da necessidade de determinação última acerca de qualquer atribuição entitativa do divino que tenha por pretensão adjudicar ao mesmo qualquer categoria ontológica.

É através da experiência dessa precariedade, proveniente dessa nossa inserção numa totalidade de mundo que excede nossa capacidade finita de apreensão fáctica dos dados sensíveis e inteligíveis, que entendemos que a abertura do sentido do ser, em seu caráter essencialmente abissal, pode tornar-se chave de compreensão para um sentido de transcendência religiosa que excede nossa própria condição fática, sem, porém, romper com a mesma. Acreditamos assim que somente a partir dessa base ontológico-existencial poderemos lidar com uma determinada "facticidade religiosa" que não se restrinja à mera dimensão empíricodedutiva e que, ao mesmo tempo, mostre-se consoante ao horizonte de sentido 
religioso da contemporaneidade marcado essencialmente pela fratura do absoluto, com a qual os mortais, sejam os de fé ou, de certa forma, mesmo os incrédulos, têm que se confrontar constantemente enquanto definem - não necessariamente de maneira teórica! - o seu estatuto existencial para além do nível ôntico ou meramente empírico, ainda que sempre em comprometimento sensível com o mesmo. Perspectiva que, segundo nossa proposta específica, deve contemplar mais de perto nosso caráter existencial de precariedade colocado em uma relação de compreensão com uma concepção do divino a partir de um horizonte de renúncia acerca do sentido último de determinação${ }^{1}$.

Mas para isso, antes, essa nossa proposta, em termos formais prévios, não pode se efetivar livremente abstraída de qualquer relação com o dado empírico, mas deve estabelecer, de maneira propedêutica, que as ordenações empíricas em geral precisam ser reportadas à sua condição de fundo mais ampla, e de caráter delimitativo em seu todo ${ }^{2}$. Sustenta-se um questionamento pela condição primeira de possibilidade dos fenômenos, sem, contudo, se arrogar à pretensão de estipular uma determinada objetivação específica para essa abertura de sentido em última instância.

Concebendo a experiência religiosa como índice radical da própria finitude humana, também tal compreensão implica fundamentalmente "o distanciamento da perspectiva que vê a relação entre Deus e o ser humano como uma dimensão isolada da vida humana ou como uma vivência interior em oposição a atitudes exteriores" (SALLES, 2010, p. 114).

\footnotetext{
1 "A possibilidade de que o próprio ser surja como a necessária precariedade dos deuses". HEIDEGGER: Beiträge zur Philosophie, p. 485. Essa precariedade está radicada no próprio ausentar-se da divindade. Isso fundamentalmente porque "faltam nomes sagrados". O que é próprio dessa falta deve ser compreendido justamente "através da experiência de sua proveniência que supostamente se vela em uma reserva do sagrado e recusa um nome de conveniência que Ihe esclareça". HEIDEGGER: Aus der Erfahrung des Denkens, p. 232. Consequentemente, também os “'deuses', porém, não são aqui pensados como o supremo, no sentido do pensamento e da poesia metafísicos de até então, mas como pertencentes à precariedade do ser". HEIDEGGER: Besinnung, p. 231. De tal forma que, em reciprocidade, "o ser é a precariedade dos deuses". HEIDEGGER: Besinnung, p. 255; cf. tb. p. 256.

${ }^{2}$ Operaríamos redutivamente se aqui tomássemos acriticamente como sinônimos as meras ordenações gerais dos dados empíricos no sentido mais técnico do termo e as abordagens teóricas de ordem analítico-empírica que, segundo justamente o que estamos propondo, podem, em um sentido mais amplo, remeter-se de maneira própria a uma forma de tratamento do fenômeno religioso, recolhido em uma chave de compreensão que não se paute somente por análises recortadas de uma determinada realidade dada!
} 


\section{Hermenêutica da finitude como meio de abordagem do fenômeno religioso}

Ao discernimento empírico cabe a função de comprovação da validade de um fenômeno em conformidade a um determinado critério eletivo aplicado estritamente a um recorte especificamente objetivo da realidade dada de imediato. Em contrapartida, a compreensão fenomenológica, em sentido filosóficoexistencial, deve cumprir a tarefa de apreensão dos fenômenos em gerais a partir da sua pretensa dinâmica essencial de fundo.

As ciências empíricas operam a partir de determinadas objetivações ou entificações daquilo que seu próprio espectro permite entender por "realidade". Procedem, sabidamente, a partir de determinadas características dos fenômenos, sem colocar-se como tarefa o questionamento pela condição de possibilidade primeira dos mesmos. Consequentemente, tanto em seu método quanto em sua constituição em geral, devem partir da validade dos pressupostos condicionados ao seu próprio campo concreto de ação, colocando em prática, uma efetividade restrita às suas próprias bases constitutivas.

Em contrapartida, a abertura fenomenológica enquanto condição de possibilidade para o sentido dos fenômenos é transcendental quando compreendida basicamente da seguinte maneira: ela excede o que é, não podendo ser reduzida a nenhuma objetivação específica. Reportado a este seu caráter fundamental de abertura, este horizonte de sentido fenomenológico não pode ser feito de “objeto" do conhecimento, não ao menos no sentido estrito do termo.

Esse deslocamento de perspectiva possibilitaria concomitantemente a mudança da questão pela essência do que seria o fenômeno substancializado para sua modalidade de sentido que se dá concretamente a partir de uma abertura de sentido de fundo como condição de possibilidade hermenêutica em aberto para as apreensões e interpretações decorrentes. Se essa forma de compreensão agora só puder ser estabelecida a partir de seu caráter modal, o sentido do fenômeno precisa 
ser compreendido a partir de sua dinâmica mais radical, que não pode mais ser fixada em um determinado sentido objetivo unívoco.

Não podendo ser assim definido em última instância através de uma determinada configuração objetivamente dada, que é através da qual, contudo, se efetiva a realidade concreta, o fenômeno em questão deve também ser necessariamente investigado a partir de sua condição essencial de abertura de sentido. Com isso, já de saída deve-se reconhecer que tal compreensão, em sua constituição essencial, não se reduz às modalidades do conhecimento que no geral têm seu modus operandi no procedimento básico de encaixar os dados empíricos positivos, que podem ser constatados de maneira sensivelmente objetivável, em construções ou sistemas lógicos específicos e previamente determinados, mostrando-se antes como condição de possibilidade para as mesmas que, por sua vez, perfazem-se como condições de efetividade para a manifestação fenomenológica dessa abertura.

Essa dinâmica fenomenológica em chave hermenêutica se constituiria, dessa forma, em horizonte relacional entre o universo empírico e um sentido de fundo que o transcende enquanto condição de compreensibilidade em aberto. Ao aberto das possibilidades interpretativas devem ser reportadas as apreensões diversas concretizadas no horizonte fáctico, que se constitui essencialmente como meio de efetivação dos fenômenos em geral. Isto nos exigirá compreender que os fenômenos não são redutíveis a dados imediatos, justamente porque eles dependem de um campo de sentido prévio, a partir do qual eles recebem suas significações possíveis.

O que é ainda preciso admitir, por conseguinte, é que aqui não há uma garantia de apreensão segura e unívoca do sentido de fundo do fenômeno, mas apenas de apreensões limitadas de determinados fenômenos situados dentro de seus contextos de tonalidades interpretativas. O que, em certa medida, vai de 
encontro ao "pathos epistemológico" moderno3. Mas que, em contrapartida, não contraria a condição de finitude fundamental do humano que compreende somente enquanto projetado numa totalidade de sentido que lhe escapa em última instância.

Ao aplicarmos essa chave de leitura no cenário religioso atual, entendemos melhor porque a maior parte das possibilidades de novas experiências religiosas que despontam na contemporaneidade, comparada aos paradigmas tradicionais, é relativamente abstrata, subjetiva ou até mesmo vaga demais para que mesmo as mais refinadas abordagens empíricas possam sistematiza-la em um enquadramento absolutamente homogêneo. E não obstante, ao menos ao que nos parece, estes horizontes de espiritualidade continuam perfazendo-se em medidas significativas como componentes essenciais de forças de uma realidade presente, ainda que essa possa ser encarada como fragmentária ou de maneira minimamente concreta, pois parecem responder ainda por certas funções ou vetores de sentidos imprescindíveis para uma parcela resiliente de vidas humanas. São experiências que não se deixam reduzir por inteiro aos espectros de apreensão que lhe são aplicadas, mas que se tornam objetivas na ação e na existência dos indivíduos, ao delimitar, ainda que em medida relativa, rumos de condutas de vida.

As alternativas atuais de ressignificação religiosa só podem - talvez mais do que nunca! - ser minimamente compreendidas segundo a percepção intersubjetiva do olhar do outro. A questão é que este "outro", lançado em esferas particionadas de realidades dinamicamente instáveis, vigora apenas parcialmente através de suas resoluções que se chocam com uma abertura de sentido que excede em muito sua capacidade de apreensão finita dos fenômenos em sua totalidade de possibilidades. Por isso é que, neste cenário, insistir em querer tratar da fé como crença em um "algo" e, de quebra, buscar analisar a plausibilidade epistemológica dessa crença escapa completamente do ponto aqui em questão. Isso não significa que só

\footnotetext{
3 A forma de procedimento aqui em questão seria melhor classificável como de ordem excessivamente "cientificista" do que propriamente "epistemológica"!
} 
possamos abordar as problemáticas religiosas em geral exclusivamente a partir de um único método, mas sim que, mesmo que ao cabo precisemos aplicar-lhes uma leitura analítica ou científica, não podemos perder de vista que, em última instância, a abertura de possibilidade para as experiências religiosas em geral repousa, de maneira fundamental, sob o olhar fenomenológico-hermenêutico (STUMP, 2010, p. 27).

De maneira complementar, as noções ainda concretamente vigentes de "religião" - ou mesmo de "religiosidade" ou "espiritualidade" em geral - estão enraizadas sob todo um arcabouço simbólico firmemente plantado através das grandes narrativas da tradição em geral. E por mais que as formas hodiernas de constituição de novos sentidos religiosos mostrem-se em sua grande maioria em um aparente desacordo com as linhas-mestras dessa tradição, não nos parece possível compreendê-las a fundo descoladas dessa tensão com seu plano precedente que, justamente em virtude desse conflito, ainda subsiste como referencial de compreensão.

Frente a esse dilema, a alternativa de entendimento que queremos sugerir aqui repousa no seguinte: o modo como a essência do fenômeno religioso em geral deve ser compreendida precisa necessariamente ser reportado a um plano existencial fundamental, tendo como referência crucial a experiência da precariedade essencialmente constitutiva de nossa própria condição de finitude que, limitada no tempo, isto é, em seu contexto histórico, tem seu horizonte de transcendência marcado por uma determinada relação de negação ou recusa do sentido do divino. Abnegação que, todavia, não deve reincidir de maneira superficial e estacionária apenas em juízos entitativos como "relativismo de valores”, “indiferentismo religioso”, "fragmentação das crenças”, "revolta ateísta”, dentre tantos outros; mas sim ser redirecionado para um horizonte de possibilidades em aberto que corresponda justamente à suspensão de toda e qualquer pretensão de se determinar em absoluto (através de categorias universais) um sentido para o abismo de fundo da experiência religiosa em geral. 


\section{Abertura de sentido como diluição do absoluto na contemporaneidade}

O que se torna fenômeno deve estar antes necessariamente resguardado por sua própria possibilidade de se manifestar. Para a apropriação desta possibilidade é necessária a fenomenologia: "Pelo fato dos fenômenos não serem dados de imediato, se carece de fenomenologia” (HEIDEGGER, 1967, p. 36). Os fenômenos não são dados de imediato justamente porque eles dependem de um campo de sentido prévio a partir do qual eles recebem suas significações possíveis. Essas significações são abarcadas pelas ciências empíricas em geral, ao passo que é a fenomenologia hermenêutica que se volta para aquela abertura de sentido enquanto condição de possibilidade para tudo aquilo que se dá. É nestes termos que a fenomenologia exige uma espécie de “passo atrás” acerca das ciências ônticas.

Como a condição de possibilidade dos fenômenos deve permanecer em aberto, isto exige de nós compreendermos que parte significativa de um fenômeno, isto é, sua própria fonte de sentido, não é de todo apreensível, consequentemente, que seu fundamento último é negado, e não afirmado tal ou qual determinada configuração específica. Daí também não poder se tratar aqui de metafísica ou teologia em sentido estrito.

Frente a essa chave de compreensão, as formas de conhecimento tradicionais só podem encontrar sua validade somente na medida em que se deixem colocar em jogo diante do que lhe excede. É através dessa limitação, inclusive, que acreditamos que a compreensão fenomenológica pode ser colocada em certo vínculo com as ciências empíricas. Pois é justamente a partir dessa confrontação que a compreensão hermenêutica tem também de assumir a impossibilidade de se apoderar de seu próprio fundamento enquanto sua condição de possibilidade. Ela deve recuar diante daquilo que lhe excede. E na medida em que é forçada a recuar, ela mesma também abre para o que lhe excede. Ela é assim lançada na própria crise do saber que tenta dizer o fenômeno em seu caráter de 
abertura, em sua transcendência abissal. E dessa distância só podemos nos aproximar na medida em que ela permanece preservada como tal. Essa compreensão aqui proposta, em sentido mais amplo, deve assim assumir um risco de defasagem que é constitutivo da própria essência do fenômeno que, enquanto possibilidade, pode também se colocar em suspenso, bem como trair qualquer pretensão de univocidade. De maneira até mesmo um tanto quanto propedêutica, acreditamos que é a partir dessa perspectiva apresentada que, de uma forma geral, a fenomenologia hermenêutica pode contribuir para ampliar o espectro de compreensão das ciências empíricas que, agindo isoladamente, nos parecem apresentar uma forte tendência a sedimentar o campo de interpretação de sentido com uma crescente exacerbação do grau de objetividade científica que visa à busca de uma segurança objetiva através do emprego prescritivo de uma racionalidade analítica e instrumental.

Em contrapartida, a finalidade da apropriação hermenêutica de todo esse círculo de compreensão consiste em preparar a possibilidade de que especialmente o estatuto da essência de fundo do fenômeno religioso possa ser compreendido fundamentalmente a partir de uma instância que se furta como tal para que determinados sentidos religiosos se possibilitem a partir desse movimento de recuo. No momento então em que pudermos pensar essa essência a partir dessa dinâmica de retração, deveremos estar prontos para assumir essa sua reserva como depositária de sentidos possíveis.

Ao se projetar - reativamente ao horizonte tradicional das pesquisas empíricas - a origem da experiência religiosa para além dos limites do entitativo, desnuda-se um ethos presente que se torna frágil ou instável diante da pretensão de sustentar concepções da deidade através de determinadas objetivações de sentido absoluto.

O postulado de certa primazia para o aspecto ontológico na abordagem do campo religioso não deve ter por pretensão a exclusão dos constitutivos ônticos 
dessa dimensão, uma vez que o eixo de compreensão existencial deve ser pautado justamente por esse trânsito, dado ser a referência maior do existencialismo aqui tomado como base justamente a concepção de um ser vincado ao mundo fáctico, do qual não pode se desprender em virtude de sua condição finita, mas também ao qual não deve se limitar por razão de seu horizonte de transcendência de sentido 4 . É esta imbricação que entendemos estar ao fundo do embate de forças de sentido que aflora na contemporaneidade5.

Neste cenário, o próprio conceito de Deus já não pode mais ser apreendido unilateralmente, sendo reportado a condições existenciais concretas, de tal forma que as experiências existenciais religiosas passam a preceder - ou até mesmo a revogar, em certos casos - as concepções tradicionalmente apriorísticas de valores absolutos e universais.

Como estamos procurando reiterar, não há aqui, ao contrário do que se possa ser levado a pensar de imediato, uma oposição hostil ou mesmo um completo distanciamento acerca das abordagens empíricas do universo religioso, posto que também as concepções científicas em geral voltadas para este campo se limitam, via de regra, a tratar da relação do homem com aqueles elementos que este mesmo compreende como dotados de sentido religioso ${ }^{6}$.

É inegável que esta proposta aqui apresentada como chave de leitura mostra-se subordinada ao horizonte de compreensão predominante na contemporaneidade, já que através dessa conjugação a noção de experiência religiosa vigente em muitos contextos pós-modernos deixa de ser uma resposta necessária do sujeito integral à concepção de uma realidade última, perdendo,

\footnotetext{
${ }^{4} \mathrm{~A}$ possiblidade de fé que subsiste aqui, em termos básicos, é a seguinte: "Fé é o que possibilita perceber a incondicionalidade presente nas realizações condicionadas". (GROSS, 2013, p. 22).

5 "Todavia, isso complica a vida daqueles que preferem ver a realidade como se ela tivesse fronteiras rígidas entre valores, idéias, pessoas. O que faz com que muitas vezes a experiência do outro seja destituída como alienada, superficial, barata, espetáculo, em pretensa oposição a uma experiência legítima, mais verdadeira, mais pura do que as outras, menos corrompida pelo mundo e seus atrativos. Uma doce ilusão. Esses aspectos estão misturados em todas as experiências, tornando-se um desafio e uma interpelação à estrutura milenar e pouco flexível da burocracia eclesiástica, enredada em disputas teológicas, portadora de uma incrivel diversificação". (SILVEIRA, 2004, p. 169).

6 "O sujeito não se coloca ao encontro do numinoso em um estado de desnudez ontológica, mas antes o faz com as vestimentas providas por um conjunto de saberes que possibilitam a constituição deste vínculo simbólico-existencial”. (LUDUENA, 2001, p. 111).
} 
concomitantemente, o estatuto exclusivista de experiência mais poderosa ou intensa deste sujeito e, ainda por conseguinte, diluindo qualquer imperativo de condução inelutável de ação. E mesmo em cenários fundamentalistas ou de pretensão de radicalização absoluta da experiência religiosa, o que temos hodiernamente é a imposição justamente da impossibilidade de efetivação plena destes postulados através do próprio conflito dirigido entre os mesmos, o que, a nosso ver, reforçaria a nossa tese da precariedade humana de fundo como condição de possibilidade para o sentido religioso em geral na atualidade, uma vez que aquilo que a limitação de nossa compreensão finita denota é a importância de não se confundir representações do real com a própria abertura de possibilidades da qual emanam os fenômenos que dão azo a essas configurações específicas7.

\section{Conclusão:}

A condição ontológica do ser finito vai ao encontro da experiência religiosa na forma aqui entendida na medida em que o mortal deve ser compreendido como lançado em um mundo de sentidos fenomênicos que o excede em totalidade apreensível. Este modo fundamental de ser no mundo perfaz-se como uma abertura a todo possível que não pode ser reduzida a uma única experiência, como tampouco objetivado por meio de um ente em definitivo. A dimensão de recusa que se abre através dessa modalidade de compreensão do horizonte de transcendência constitui uma fratura ou uma espécie de hiato relacional que precisa ser entendido como margem de ação para uma experiência de precariedade frente à abissalidade da totalidade dos fenômenos possíveis em última instância. Os novos movimentos religiosos ou espirituais que em geral se configuram através das mais variadas modalidades ônticas presentes na contemporaneidade devem ser, assim, fundamentalmente relacionados a uma certa percepção de fundo da insuficiência humana. E é de extrema importância que tal análise, em seu fundo ontológico, se

\footnotetext{
${ }^{7}$ Sabemos que, em se tratando justamente de um universo extremamente multifacetado, não podemos cindir a(s) "realidade(s) pósmoderna(s)" em apenas dois polos exclusivos de sentido! Todavia, o que tomamos aqui como campo de ação central quanto a essa questão específica é constituído basicamente por dois paradigmas interpretativos possíveis que nos parecem poder ser compreendidos como significativamente vigentes e relativamente aglutinadores em meio ao horizonte fragmentário da contemporaneidade!
} 
paute para aquém de quaisquer referências valorativas, uma vez que estas só encontram sua legitimidade possível e relativa em meio aos contextos sociais, históricos e culturais, isto é, a partir da dimensão ôntica e derivada do mundo fenomenológico.

Compreendida sob esta chave de leitura, a emergência de novos movimentos religiosos ou espirituais, bem como de seus decorrentes efeitos desreguladores dos parâmetros tradicionais, podem permitir a ressignificação de um amplo potencial de criações de sentidos ou modalidades de ser no mundo através das mais variadas experiências para além daquelas que as instituições religiosas tradicionais historicamente pretenderam direcionar e objetivar de maneira unívoca por meio de suas racionalidades discursivas de pretensões absolutistas. Sob esta ótica, a contemporaneidade tornar-se-ia um terreno fértil para a subsistência de novas alternativas religiosas que portariam em sua essência uma constante dinâmica de revitalização de possibilidades de sentidos em aberto redutíveis a um horizonte de transcendência de fundo inobjetivável como tal.

\section{REFERÊNCIAS}

CRUZ, Eduardo R.; MORI, Geraldo de (Org.). Teologia e ciências da religião. A caminho da maioridade acadêmica no Brasil. São Paulo: Paulinas, 2011.

GROSS, Eduardo. O conceito de fé em Paul Tillich. Revista Eletrônica Correlatio. v. 12, n. 23, p. 7-26, Junho de 2013.

HEIDEGGER, Martin. Aus der Erfahrung des Denkens. 2. Aufl. Frankfurt am Main: Vittorio Klostermann, 2002 [1983] (Gesamtausgabe: 13).

HEIDEGGER, Martin. Beiträge zur Philosophie (Vom Ereignis). 3. Aufl. Frankfurt am Main: Vittorio Klostermann, 2003 [1989] (Gesamtausgabe: 65).

HEIDEGGER, Martin. Besinnung. Frankfurt am Main: Vittorio Klostermann, 1997 (Gesamtausgabe: Bd. 66).

HEIDEGGER, Martin. Sein und Zeit. 11. Aufl. Tübingen: Max Niemeyer, 1967. 
LUDUENA, Gustavo Andrés. Dos Experiencias Místicas do lo Numinoso. Numen. Juiz de Fora. v. 4, n. 1, p. 87- 118, 2001.

SALLES, Walter F. O pluralismo religioso e a dimensão hermenêutica da identidade cristã. In: SOUZA, Ney de (Org). Teologia em diálogo. Os desafios da reflexão teológica na atualidade. Aparecida: Santuário, 2010. p. 103-125

SILVEIRA, Emerson J.S. Pluralidade Católica: um esboço de novos e antigos estilos de crença e pertencimento. Sacrilegens. Juiz de Fora. v.1, n.1, p. 153-174, 2004.

SOUZA, Ney de (Org). Teologia em diálogo. Os desafios da reflexão teológica na atualidade. Aparecida: Santuário, 2010.

STUMP, Eleonore. Wandering in Darkness. Narrative and the Problem of Suffering. Oxford: Clarendon Press, 2010.

WACHHOLZ, Wilhelm. Por uma Teologia como ciência e pela ecumene das ciências. In: CRUZ, Eduardo R.; MORI, Geraldo de (Org.). Teologia e ciências da religião. A caminho da maioridade acadêmica no Brasil. São Paulo: Paulinas, 2011. p. 198-216. 